\title{
Time to make haste
}

\section{Scientists with a busy schedule must free up time to develop professionally in a fast-moving sector.}

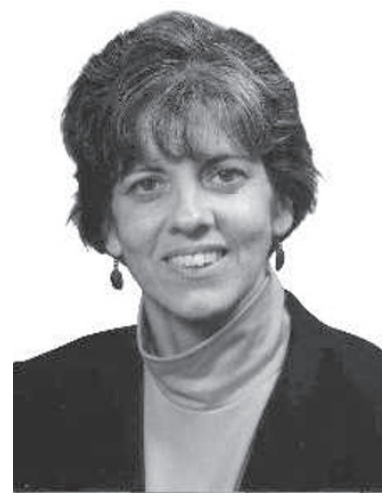

Deb Koen
Scientists often don't know the best way to incorporate professional development into already busy research schedules. It's a theme that frequently emerges in my presentations and conversations with the research community. In fact, scientists can't afford not to carve out at least a portion of their time for career development. Those who decline are not only standing still but losing ground. With precious little warning, a skill set you're wedded to can become obsolete, while new priorities arise almost overnight. Whether you live in the lab, carry a full teaching course load or manage a research division, it's important to make development a priority. Translating intention into action is the key. Here's my top-ten checklist of success strategies.

\section{Play to your strengths}

Being true to yourself is the only solid foundation on which to build a career. When you consider career development, avoid the tendency to focus only on weaknesses to the exclusion of your strengths. Instead, concentrate your efforts on work that gives you personal satisfaction while leveraging your strong points.

\section{"With little warning, a skill set you're wedded to can become obsolete."}

or play an advocacy role. Act on opportunities to contribute to the individual's career growth. Whether recommending a course, making a connection to an influential researcher for a mentee or passing along information on openings, your efforts to help another will result in a shared learning experience.

\section{Study your organization}

With an all-consuming schedule, it's easy to operate in a vacuum. The danger with having too narrow a focus is that while you're busy working hard, your goals may fall out of line with your organization's. Camera maker Eastman Kodak, for example, had to deal with a revolutionary wave of digital technology: employees who saw it coming tweaked their skill sets and career paths; others found themselves out of a job. Broaden your perspective to allow for changing trends and career advancement.

\section{Target a trend}

Expand your study beyond your current research to stay informed of developments in your field, as well as the social, political and economic realms. Governmental regulations in stem-cell research or increased focus on and money for biofuels research, for example, could have an impact on career development choices. It's no secret to scientists that research initiatives fall in and out of favour with various social movements and changes in political administrations. Consider joining the World Future Society (www.wfs.org) for a big picture look at predictions. as a boss, mentor or colleague, for suggestions on how to improve your work, your style and your approach. View their insights as gifts.

\section{Bring someone else along} Develop yourself by developing others. Get a picture in your mind of someone to whom you would like to reach out. Maybe you'll become an active mentor

\section{Build your brand}

Branding involves developing and managing your reputation through your results and your relationships. Track professional accomplishments by keeping a career file, constantly looking for what makes you unique. Communicate your brand through a CV or resumé, presentations (formal and informal), a website, if you have one, and any other relevant marketing materials.

\section{Adopt a healthful practice}

Healthy habits are easily crushed under mounting workplace pressures. With sedentary roles and stressful environments, it's unlikely that your need for exercise, nutrition, spiritual renewal and relaxation will be met without conscious effort. Through meditation, a yoga class or a buddy system, embracing a healthful practice is essential to your overall development.

\section{Pick a new constituency}

There's probably a constituency out there that you've been meaning to reach out to. Whether you contact funders, focus on your lab mates or become active in a scientific association, connecting to an overlooked group could enhance performance and contribute to your professional development.

\section{Stretch your boundaries} Specialization is necessary but not sufficient in a world where international connections and contacts are increasingly important. Diversify your relationships. Mingle with new groups. Frequent places you've never been. Read books and journals out of your discipline. In essence, develop by broadening your perspective.

\section{Simplify}

Given that researchers are generally extremely busy, it's difficult to focus on all ten strategies here. To maximize your time and energy, figure out what complicates your life and then set out to simplify. In addition to simplifying, select and apply two other strategies that best reflect your development interests. Deb Koen is the president and CEO of Career Development Services in Rochester, New York. 